\title{
Cuando los otros importantes eran siempre "ellas"
}

\author{
When women were always the other important ones
}

Universidad de Valladolid

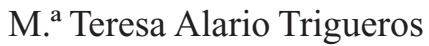

talario@arte.uva.es

Recibido el 25 de enero de 2017

Aceptado el 27 de septiembre de 2019

[1134-6396(2019)26:2; 575-605]

http://dx.doi.org/10.30827/arenal.v26i2.5580

\section{RESUMEN}

Chadwick y Courtivron analizaron en su obra Los otros importantes el espacio creativo que se generaba entre aquellos artistas que formaron pareja sentimental. Frente a la historiografía tradicional en que describía la creatividad como la lucha solitaria de un individuo (normalmente un hombre), estas investigadoras planteaban que en el caso de las parejas de artistas la interrelación de vidas y obras debería hacer que necesariamente el influjo tuviera que ser mutuo. Sin embargo, la obra de las artistas sigue siendo interpretada como dependiente la de la parte masculina de la pareja.

En la historia del arte español contemporáneo esta situación se acentuó como consecuencia de las condiciones socioculturales del periodo franquista, en el que nombres como el de Magda Bolumar fueron invisibilizados, aunque va más allá del marco cronológico de este período, afectando en pleno siglo XXI a artistas como Patricia Gadea.

Palabras clave: Mujer artista. Pareja. Influencia. Invisibilidad. Arte contemporáneo. España.

\begin{abstract}
Chadwick and Courtivron analyzed in their work The others important the creative space generated between those artists who were couple. Facing the traditional historiography where the creativity was described as the individual lonely battle (usually a man), these women researchers considered that in couple artists the interrelations of their lives and work will make the influence to be mutual. Nevertheless, the work of the woman artist is still being interpreted as dependent of the male part of the couple.

In the Spanish contemporary Art History this situation was emphasized as the consequence of the sociocultural conditions of the Francoist Period, in which names as Magda Bolumar were made invisible, although this happens further than this chronological period affecting even to 21 st Century artists as Patricia Gadea.
\end{abstract}

Key words: Woman artist. Couple. Influence. Invisibility. Contemporary art. Spain. 
Es un hecho conocido que uno de los mecanismos utilizados en la historiografía artística para minimizar la figura de las artistas e invisibilizar su obra ha sido presentarlas como dependientes de los hombres con quienes estuvieron relacionadas por lazos de parentesco o afecto. De este modo, se suele citar a una artista haciendo referencia a que fue hija, esposa o amante de algún conocido artista — cuya obra es considerada explícita o implícitamente de mayor categoría artística que la de ella- y, más o menos sutilmente, se establece una cierta dependencia estilística respecto a él. Incluso en bastantes ocasiones las obras de las creadoras se han atribuido a sus maridos o amantes.

Este tema ha sido tratado por muchas investigadoras e investigadores aunque poniendo el acento en distintos aspectos. Germaine Greer se refirió de un modo específico a las relaciones de pareja entre artistas en la última parte de su conocido libro La carrera de obstáculos, utilizando un término tan duro como "saqueo" al tratar sobre el ocultamiento y la desvalorización de la obra de las artistas tras las trayectorias de sus compañeros sentimentales, llegando a la conclusión de que:

El primer requisito es el conocimiento, no sólo de la obra de las mujeres, sino de la obra de los hombres relacionados con ellas, y no con generalizaciones sino con ejemplos precisos (...) entender cómo las artistas a veces guiaron a los hombres, fueron saqueadas y adelantadas después, es una parte de la recuperación de nuestra historia ${ }^{1}$.

De este modo Greer plantea la necesidad de analizar las influencias mutuas frente a la visión unidireccional que ha dominado en el análisis de las relaciones sentimentales y/o de pareja entre artistas, al ser tratado únicamente como un factor limitante para el desarrollo y reconocimiento de la obra de una de las partes: la femenina.

En este sentido, es evidente que los casos de falsas atribuciones, renuncias, y minusvaloración de la obra de las artistas por razón de género también se ha dado en la historia del arte español hasta prácticamente la actualidad. Pero es también cierto que cabría plantear otras preguntas, referidas no sólo a lo que esta situación ha limitado el reconocimiento de la obra de las mujeres, sino también lo que ha aportado la relación afectivo-sentimental al arte de ambos: ¿cuáles han sido los efectos positivos y negativos para hombres y mujeres?

Cuando Mihàly Csikszentmihalyi ${ }^{2}$ se refiere a los componentes que interactúan dentro del sistema creativo, utiliza el concepto de "cónyuge sostenedor", definido como aquel que facilita una vida afectiva - y generalmente también material—

1. GREER, Germaine: La carrera de obstáculos. Vida y obra de las pintoras antes de 1950. Madrid, Ediciones Bercimuel, 2005. p. 336.

2. CSIKSZENTMIHALYI, Mihàly: Creatividad, el fluir y la psicología del descubrimiento y de la invención. Madrid, Paidós, 1998, p. 22. 
satisfactoria que pudiera en principio referirse indistintamente a "él" o "ella". Pero Csikszentmihalyi concluye que "ese cónyuge sostenedor ideal es mucho más difícil de encontrar si ese individuo creador es una mujer. Podríamos aventurar incluso que, de existir un análisis de género en la construcción de la persona creadora, sería conveniente añadir el concepto de "cónyuges obstaculizadores", en el caso femenino"3. Entonces surge la pregunta: ¿qué sucede con la figura "cónyuge sostenedor" cuando el individuo creativo es una mujer?, ¿y cuando las dos personas que componen la pareja son artistas?

En este mismo sentido y partiendo del cuestionamiento en la teoría feminista del concepto de Genio, sobre el que ha pivotado gran parte de la historia del arte oficial, Chadwick y Courtivron analizaron en su obra Los otros importantes el espacio creativo generado entre los y las artistas que formaron pareja sentimental. Frente a la historiografía tradicional, en la cual "las biografías y las monografías tradicionales suelen describir la creatividad como la lucha solitaria de un individuo (normalmente un hombre) por la expresión artística (...) decidimos explorar las complejidades de varias asociaciones y colaboraciones dolorosas y enriquecedoras" ${ }^{\prime}$. De este modo estas investigadoras planteaban que la interrelación de las vidas y las obras hacían que necesariamente el influjo fuese mutuo. Sin embargo la asimetría con que se ha tratado este tema queda patente en lo acostumbrados que estamos a leer en un catálogo, una crítica o texto académico que alguien fue "mujer artista, pero también mujer de artista"s, pero nos extrañaría tremendamente una frase similar referida a una varón.

Frente a la noción de individualidad el equipo de investigación dirigido por Chadwick y Courtivron se cuestionó las relaciones entre aquellas parejas que "han compartido sexualidad y creación". ¿Se puede ser genio en solitario?, ¿se puede seguir manteniendo el mito del aislamiento, del individualismo del Genio?, ¿como separar en el arte las interrelaciones y las influencias que se dan en la vida?, eran las preguntas con que se iniciaba el citado libro.

¿Qué ha sucedido en el caso del arte contemporáneo español? Como decía Estrella de Diego al tratar sobre las pintoras del siglo XIX ${ }^{6}$, este mecanismo se ha

3. LÓPEZ-FERNÁNDEZ CAO, Marián: "Del mito de la creatividad pura a un enfoque sistémico", web m-arte y cultura visual, 2014. http://www.m-arteyculturavisual.com/2012/10/15/ del-mito-de-la-creatividad-pura-a-un-enfoque-sistemico-de-genero-en-la-construccion-de-la-personacreadora/ (consultado 1 de julio de 2014).

4. CHADWICK, Whitney y COURTIVRON, Isabelle (eds.): Los otros importantes. Creatividad y relaciones intimas. Valencia, Cátedra, 1994. p. 9.

5. Catálogo de Juana Francés. Zaragoza, IAACC Pablo Serrano. Gobierno de Aragón. 2012.

6. "Este es otro de los lugares comunes más tristes a la hora de hablar de las pintoras (...) pensar siempre que un hombre (padre, marido o maestro) le ha pintado la obra". DE DIEGO, Estrella: La mujer y la pintura del XIX español. Madrid, Cátedra, 1987. p. 253. 
mantenido bajo ropajes diversos y con distinta intensidad en nuestra $\mathrm{H} .{ }^{a}$ del Arte, llegando hasta el XXI.

Las parejas de artistas han sido algo habitual a lo largo de nuestra historia, ya que era más fácil que una mujer se dedicara al arte si tenía un marido o compañero sentimental que también era artista. Es decir, había mayor permisividad para una mujer que desease se artista si su pareja también lo era.

Esta solución fue especialmente lógica para las artistas en la España del franquismo, en que las mujeres tenían una mayor dificultad para moverse con la mínima libertad que la dedicación al arte demandaba. Aquellas que orientaron su trayectoria vital y profesional hacia la actividad artística encontraran menores dificultades si estaban emparejadas con otros artistas. Por ello las parejas artísticas abundaron en el panorama artístico de la vanguardia española posterior a la guerra civil ${ }^{7}$.

Aunque la nómina de parejas artísticas de ese periodo no se agota en las que aquí se van a citar, cabe destacar los nombres de las pintoras Juana Francés, ligada sentimentalmente al escultor Pablo Serrano, Jacinta Gil, casada con el pintor Manuel Gil, la también pintora Amalia Avia, casada con Lucio Muñoz, María Moreno con Antonio López, la pintora Isabel Quintanilla con el escultor Francisco López Hernández o Esperanza Parada, pareja del también escultor Julio López Hernández.

El contexto histórico que se vivía en España impedía cualquier cambio que permitiese ver como natural la incorporación de las mujeres como miembros de pleno derecho en el arte contemporáneo ${ }^{8}$. Por ello, cuando se revisa la "historia oficial" de las vanguardias en la España de postguerra, la figura de mujer artista está desdibujada, aparece como una sombra. Cuando se consulta cualquier obra sobre los grupos que renovaron el arte español tras la guerra civil, lo más habitual es encontrar a lo sumo dos o tres nombres de mujeres artistas cuya obra es además tratad de un modo bastante epidérmico. Los nombres de artistas emparejadas con otros pintores o escultores aparecen como comparsa con escasa o nula importancia en el medio artístico, o más bien, como necesario contrapunto que engrandece la figura de los artistas, sus esposos o amantes, como puede verse en las monografías publicadas sobre ellos. Ellas constituían un elemento fundamental para que siguiera funcionando el mito del "artista varón, independiente y superior", para que la narración sobre el genio mantuviera su eficacia.

La interpretación sexual del Genio como masculino es evidente cuando se habla de la inspiración, representada en la musa: "Si se piensa un poco, la musa es la mujer ideal, salvo por el hecho de no estar siempre disponible y resultar

7. Ver LÓPEZ MUÑOZ, Pilar: Mujeres españolas en las artes plásticas. Madrid, Síntesis, 2003; y LÓPEZ MUÑOZ, Pilar: “Artistas españolas en la dictadura de Franco (1939-1975)". Espacio, Tiempo, Forma, 3 (2015).

8. "Los contextos históricos y las condiciones intelectuales también fomentan (o estorban) la diversidad y los paradigmas nuevos". CHADWICK, Whitney y COURTIVRON, Isabelle (eds.): op. cit., pp. 15-16. 
frecuentemente esquiva, pero cuando se entrega, se entrega". El Genio artístico es, por principio, masculino. Desde el Romanticismo, época de la originalidad y la libertad creadora en que se define la figura del artista como héroe, se fija la imagen del artista con los atributos masculinos y, en ese sentido, no hay ningún tipo de ruptura en las vanguardias. Buen ejemplo de ello es uno de los puntales del Informalismo en España: el grupo El Paso.

La figura del artista llevaba implícita el disfrute de la libertad y la independencia, mientras el mandato de género obligaba a las mujeres a ser dependientes y sometidas - de un modo especialmente marcado en la España franquista — por lo que las artistas estaban abocadas a vivir una contradicción profunda y con difícil salida. Por ello estas artistas-esposas suelen ser tratadas en las publicaciones como figuras menores, ante las cuales la figura del esposo se agiganta, ya que el/ la biógrafo/a se cuida de destacar su labor fundamental en el entorno del gran artista. Ellas aparecen como figuras permanentemente atentas a sus necesidades cotidianas, cuidadosas de atender a sus deseos. Aparecen también como gestoras eficaces de su obra, incluso cuando el artista-esposo ha desaparecido. Se les atribuye, por tanto, un papel secundario aunque asumido de modo aparentemente voluntario. Esta situación lleva aparejada el no reconocimiento de la trayectoria profesional de ellas, a quienes como mucho se les concede el reconocimiento de camino compartido, de formar parte de la trayectoria "de pareja".

El paso siguiente que subyace en este paradigma es la mayor debilidad en la obra de las mujeres que, en muchas ocasiones, se considera mera continuación o imitación debilitada de la de sus esposos y compañeros. En ese sentido Greer destaca "la fácil hipótesis que se hace sobre pintores y pintoras muy unidos de que un hombre lleva y la mujer le sigue. Lo que concuerda con el estatus de ella como imitadora y asume que las diferencias en el punto de vista evidencian inferioridad o incompetencia" 10 .

La asunción de esa inferioridad ante el varón-genio por parte de las artistas podía llegar a ser paralizante y disuasoria para la creación de las mujeres. Un ejemplo de ello es el de Elvireta Escobio, esposa de Manolo Millares, uno de los míticos creadores de la abstracción informalista española. Elvireta y Manolo se conocieron en el año 1946, cuando ella sólo tenía 14 años y él 20. La propuesta de noviazgo llegó poco tiempo más tarde y se casaron 7 años después de conocerse. Elvireta formó parte del grupo de intelectuales que editó la revista Planas de poesía, creado en 1949 en Las Palmas, y de LADAC (Los Arqueros del Arte Contemporáneo), uno de los primeros grupos plenamente abstractos en el panorama

9. GUILLÉN, Esperanza: Retratos del genio. Culto a la personalidad artística en el siglo XIX. Madrid, Cátedra, 2007, pp. 57-58.

10. GREER, Germaine: op. cit., p. 104. 
de la vanguardia española. Este grupo, surgido en las Palmas de Gran Canaria, aportaba a la abstracción un toque de indigenismo ${ }^{11}$.

Manolo Millares rememora en Memorias de infancia y juventud ${ }^{12}$, la íntima colaboración que en esta fase de su trayectoria había entre él y Elvireta. Así escribe refriéndose a la publicación de la colección de monografías titulada "Arqueros" que se inició en el año 1950: "Elvireta me ayudaba mucho en todos estos trabajos y lo hizo muy bien".

Manolo Millares veía en Elvireta una ayuda inestimable para llevar a cabo sus proyectos, destacando el apoyo que ella le prestó para llevar a cabo la exposición de dibujos de la Joven pintura española en el recién creado Club de Universitarios en el año 1953, en la que también figuraban Tapies y Antonio Saura. Pero además en aquellos años Millares ve también en ella a una pintora autónoma con obra artística valiosa y de interés:

El caso de Elvireta era en particular interesante. Enormemente dotada para el arte, pintaba unos cuadros con una técnica casi oriental de gran sensibilidad. Su imaginería tenía cierto entronque con los pintores naifs, si bien sobrepasaba ese mundo ingenuo para adentrarse en una problemática mucho más actual llena de fuerza (aunque esta no se palpaba tan fácilmente). Tal vez será más exacto si hablara de una fuerza sublimada por la ternura" ${ }^{13}$.

Una muestra de que la creatividad de Elvireta era valorada en los círculos de la vanguardia en esos momentos es la colaboración entre la pintora, Millares y Martín Chirino en la ilustración del libro de Manolo Padorno Oí crecer a las palomas. Además Elvireta realiza también varias exposiciones colectivas que se entre 1952 y 1955 en varias localidades de las Canarias. El propio Millares en sus Memorias de infancia y juventud hace énfasis en una exposición colectiva en la cual, entre otros, participa la pareja antes de salir definitivamente de la isla: "organizamos una exposición colectiva (Escobio-Chirino-Szmull y Millares) en el Museo Canario. Fue la exposición más interesante que se hizo en Las Palmas en un montón de años" ${ }^{\prime 14}$. En 1953 la pintora participa también en una exposición con Millares y Palau Ferre en la Galería Clan.

Sin embargo, según avanza la década de 1950 se produce un cambio en el papel que se va atribuyendo a la figura de Elvireta. De ser mencionada como miembro de pleno derecho de LADAC, pasa a ser citada exclusivamente como compañera y testigo de hechos y situaciones fundamentales en la vanguardia española de aque-

11. Participó realizando dibujos para varios números de la revista (n. 3 y 14). http://www. academiacanarialengua.org/archipielago/planas-de-poesia/ (Consultado el 19 de enero de 2017).

12. MILLARES, Manolo: Memorias de Infancia y Juventud. Valencia, IVAM, 1998.

13. MILLARES, Manolo: op. cit., p. 130.

14. MILLARES, Manolo: op. cit., p. 130. 
llos años, y como elemento desencadenante de decisiones claves en la trayectoria vital y artística de Millares.

Por ejemplo Valeriano Bozal, al analizar la figura de Millares, señala la fecha de 1955 como fecha clave que le permite romper con su isla natal y poco después constituir El Paso, pues "vende sus muebles y con Elvireta Escobio, Martín Chirino, Alejandro Reina y Manolo Padorno toma el barco, el Alcántara, hacia la Península. El destino final es Madrid" ${ }^{15}$. Hay en esta narración de la decisión de la partida un punto de heroísmo que cuadra a la perfección con el mito romántico del artista. Sin embargo, en la película Cuadernos de contabilidad de Manolo Millares ${ }^{16}$ Elvireta cuenta que fue ella la que animó a la marcha definitiva y tomó la decisión de vender los muebles que constituían todas las posesiones de la pareja, reducidas a las 40.000 pesetas, lo que les permitió subsistir durante algún tiempo.

En la crónica que realiza Francisco Calvo Serraller de los 50 años del arte español posteriores a la guerra civil ${ }^{17}$ cita a Elvireta en tres ocasiones. En las dos primeras como miembro fundador de la revista Planas de Poesía y de LADAC correspondientes a la crónica de los años 1949 y 1951 respectivamente. Pero su

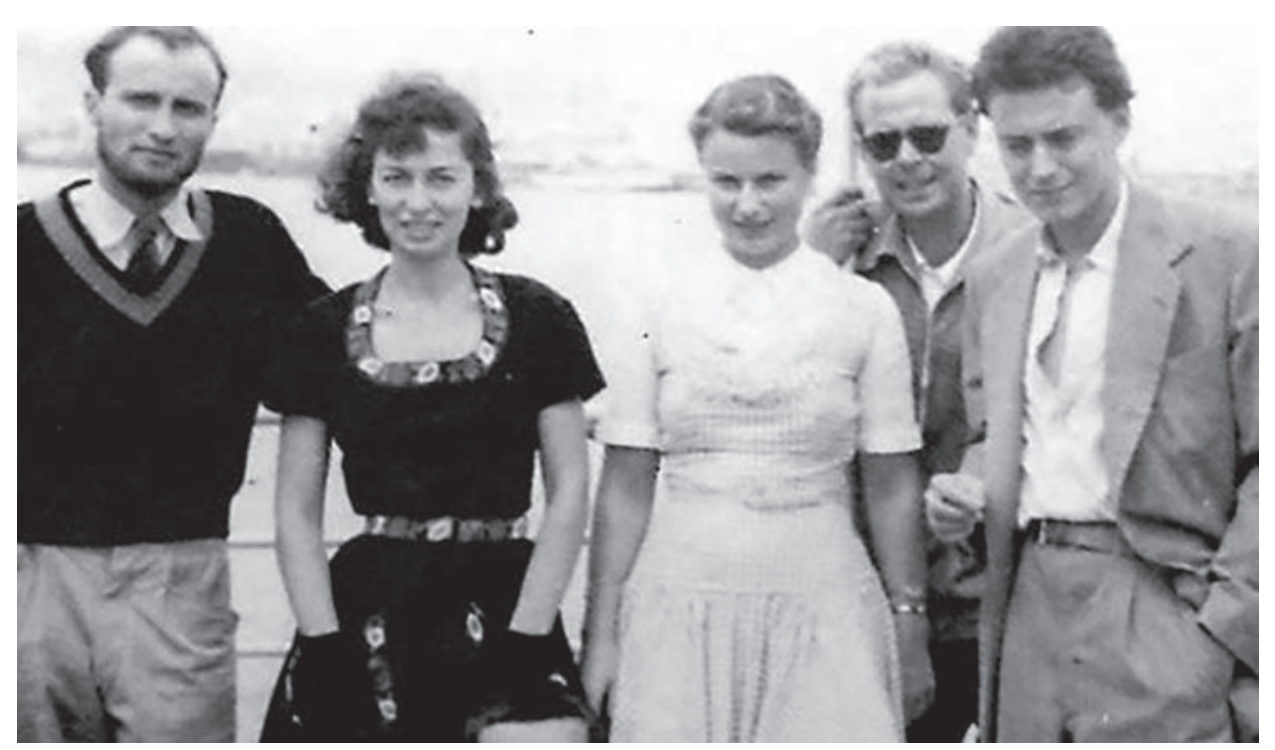

Fig. 1. Elvireta Escobio con Millares y otros miembros del grupo El Paso.

15. BOZAL, Valeriano: Arte del siglo XX en España (T. 2) Madrid, Espasa Calpe, 1995, p. 412.

16. Documental dirigido por Juan Millares Alonso, 2005.

17. CALVO SERRALLER, Francisco: España medio siglo de arte de vanguardia 1939-1985, Madrid, Fundación Santillana, Ministerio de Cultura, 1985. 
nombre no vuelve a aparecer hasta el año 1973 en el pie de foto que ilustra la noticia sobre la exposición Homenaje a Millares que se realizó tras el fallecimiento del pintor. En este puede leerse "Lucio Muñoz, Juana Mordó, José Ayllón y Elvireta Escobio, mujer de Millares". La aclaración final — mujer de Millares - implica que Elvireta no aparece siquiera como compañera de trayectoria artística de Millares, sino como viuda del pintor, cuya muerte joven y en plena etapa de reconocimiento de su obra encaja plenamente con el mito romántico del genio.

El papel de viuda que consagra su vida a la obra del gran artista, había sido ya asignado a artistas como la pintora americana Lee Krasner. También Krasner se convirtió en la guardiana de la obra de Pollock tras la trágica y temprana muerte de éste. Y aunque efectivamente Krasner se dedicó hasta el final de sus días a gestionar el legado de su marido, ella se quejó en varias ocasiones de que no se la viese como pintora, sino únicamente como viuda. Este hecho se evidencia por ejemplo, en que en los dos libros de referencia sobre el Expresionismo Abstracto ${ }^{18}$ no se menciona su nombre. Y esto mismo sucedió con Elvireta Escobio. Hasta el punto que en entrevistas que se le han realizado no se cita en absoluto su actividad artística. En la entrevista que le hizo Teresa Iturriaga ${ }^{19}$ se hacía hincapié en su papel como testigo de excepción de ese periodo, por ser "compañera y eco de la voz del artista Manolo Millares". De este modo introduce la entrevistadora la conversación: "Hoy pedimos a Elvireta Escobio (...) que nos hable de los recuerdos de su infancia en Las Canteras. Nadie como ella podría hablarnos mejor del hombre y del niño que se escondía en el artista". Y prosigue en un tono paternalista que sería impensable en el caso de un varón:

Sorprende la voz de Elvireta, tan joven, tan optimista y, a la vez, tan razonable... Hay en su timbre de voz un ritmo de cascabeles, hay alegría de olas, hay un canto que te lleva. Y, sin embargo, no hay duda de que en su vida habrá sufrido como cualquier ser humano sensible.

Volviendo al caso de Lee Krasner, Anne M. Wagner analiza en su ensayo titulado "Ficciones. Presencia de Krasner, ausencia de Pollock" ${ }^{20}$ el modo en que, tras la muerte de Pollock y de la propia Krasner, se refuerza el mito del artista maldito, y en este drama se construye para ella un "personaje": el de esposa-viuda. Un personaje que fagocita a la figura de la pintora. Como dice Wagner, desde la crítica feminista habría que intentar contar otro relato, pero "no era posible separar

18. SANDLER, Irving: The Triumph of American Painting. Harper \& Row, 1970; y SEITZ, W. C.: Abstract Expressionist Painting in America. Cambridge, Harvard University Press, 1983.

19. http://www.miplayadelascanteras.com.

20. WAGNER, Anne M.: "Ficciones. Presencia de Krasner, ausencia de Pollock". En CHADWICK, Whitney y COURTIVRON, Isabelle (eds.): Opus Cit, pp. 277-304. 
su yo pictórico de su contexto social. Los deberes de una viuda en la gestión del legado eran arduos, por decirlo suavemente" ${ }^{21}$.

Posiblemente ese relato es lo que pudo también a Elvireta Escobio. La enfermedad y muerte joven y en pleno éxito de Millares se ajustaban perfectamente al mito del artista romántico que había consumido su vida en una actividad creativa y trasgresora de los límites, en su esfuerzo de abrir puertas al futuro del arte. A ella le correspondería convertirse en la fiel compañera, aliada y guardiana de su memoria y de su obra.

Sin embargo, Elvireta Escobio tuvo también parte activa en el rodaje de un documental sobre la obra de Millares en $1970^{22}$ y más tarde, ya tras la muerte del pintor, participó con su hija Eva en la producción de la película Cuadernos de contabilidad de Manolo Millares. En el año 1996 se publicaba un poemario de Elvireta Escobio con dibujos de Manolo Millares que llevaba por título De un espacio sin tiempo. Sin embargo de la Elvireta pintora no se ha vuelto a tener conocimiento público.

Una trayectoria muy diferente a la de Elvireta fue la de la pintora que más reconocimiento logró en el Informalismo español: Juana Francés. Su proximidad a los círculos de la vanguardia informalista y el hecho de ser mujer, además de la coincidencia generacional, es lo que acerca a ambas. También en este caso, la artista "sufrió la sombra de estar casada con otro artista"23.

Desde niña Juana Francés fue preparada para dedicarse profesionalmente a la música, aunque finalmente se orientó hacia la pintura, matriculándose en la madrileña Escuela de San Fernando. Finalizados sus estudios, una beca le permitió viajar a París, donde vio las obras de sus admirados impresionistas, pero también de Paolo Ucello, Mantegna o Piero de la Francesca, cuyo dominio constructivo habría de estar presente en la obra que la artista desarrolló posteriormente.

Juana expuso por primera vez en solitario en 1952 en la Galería Xagra de Madrid; más tarde llegarían la participación en la Bienal de Arte de Venecia (1954) y en la I, II, y III Bienales Hispanoamericanas de Arte (1951,1953 y 1955) y posteriormente en la Bienal de Alejandría (1959).

En poco más de un lustro Juana llegó al Informalismo, tras una etapa figurativa en la que había conseguido dar gran protagonismo a las texturas a partir del uso de la espátula. Hay que recordar el I Curso de Arte Abstracto, que se celebró en Santander en 1953 e hizo especial mella en Juana, como en muchos artistas de su

21. Ibidem p. 298.

22. "Trascurre el invierno de 1970 y Millares rueda una película sobre sí mismo. Detrás de la cámara, su mujer, Elvireta, compañera suya desde la época de Planas de poesía, allá en las Palmas". MILLARES, E. Catálogo de la Exposición Millares. Luto de oriente y occidente. Las Palmas de Gran Canaria, SEACEX, 2003, p. 131.

23. MARZO, José Luis y MAYAYO, Patricia: Arte en España (1939-2015). Ideas, prácticas, políticas. Madrid, Cátedra, 2015. 
generación. Juana Francés fue una artista pionera. Tras un proceso de investigación formal en que investiga en técnicas diversas, trabajando con capas de pintura superpuestas, en 1956 había ya eliminado la figuración de su obra, "construida con fondos grises con manchas blancas y rojas de gran dinamismo" 24 y comienza a sustituir el óleo comienza por arenas y materias plásticas. Como describe Natalia Molinos en este momento Juana Francés "pasa del lienzo pintado en vertical sobre caballete a lanzar pintura y materia sobre el lienzo posado horizontalmente en el suelo" 25 .

Fue en ese año cuando, en la exposición de Juana que se celebraba en el Ateneo de Madrid, conoció al escultor Pablo Serrano, casi veinte años mayor que ella y con una reconocida trayectoria vanguardista.

A pesar de que ya en 1953 en su pintura se reconoció un germen de renovación por hacer "una pintura de hoy, es decir, acorde con la expresión necesaria y próxima del artista actual" 26 , a pesar de que antes de finalizar la década de 1950 Juana Francés fue considerada por la crítica como "uno de los más seguros valores de la joven pintura nacional" 27 , el dato que nunca falta y se destaca en cualquiera de los perfiles biográficos que se han hecho de la artista es su relación sentimental con el escultor Pablo Serrano. Y aunque éste es evidentemente un dato importante en la vida y la obra de la pintora ${ }^{28}$, su repetición y la preeminencia que se le da para nada comparable en el caso de las biografías de los artistas varones también casados o emparejados con conocidas artistas- parece sugerir la supeditación de su obra a su condición de esposa de artista, e incluso alienta la sospecha de que su condición como tal tenga algo que ver con el reconocimiento de su obra.

Juana Francés fue una magnifica artista, con una trayectoria muy personal, que hubo de luchar contra lo que suponía ser "pareja de". En ese sentido Juana podría haber hecho suyas las palabras de Lee Krasner al referirse al crítico H. Rosemberg: "cada vez que se habló de mí después de la muerte de Pollock siempre decía "Lee Krasner, la viuda de Jackson Pollock", como si me hiciera falta ese título" ${ }^{29}$. A Juana el título que le acompaño fue el de "joven esposa/compañera", con lo que ello implicaba de posible emulación y "copia empobrecida" de la obra del varón.

24. URUEÑA, Gabriel: Las vanguardias artísticas en la postguerra española. Madrid, Istmo, 1982, p. 261.

25. MOLINOS NAVARRO, Natalia: "Juana Francés. Una vocación, una pasión”. En VV.AA.: Catálogo de Juana Francés. Zaragoza, IAACC Pablo Serrano. Gobierno de Aragón, 2012, pp. 11-48.

26. Texto de Manuel Conde para el catálogo de la exposición de Juana Francés en la Galería Biosca, en 1953. Recogido en CALVO SERRALLER, Francisco: España medio siglo de arte de vanguardia 1939-198. Madrid, Fundación Santillana/Ministerio de Cultura, 1985, p. 327.

27. CASTRO ARINES, José: Informaciones, martes, 9 de junio de 1959.

28. "Fue hallar el amor a la vez que un camarada para recorrer juntos el camino del arte", decía la pintora al referirse a su encuentro con Serrano. ARAZO, M. A.: "Juana Francés". Diario Las Provincias. Valencia, 16 de octubre de 1980.

29. CHADWICK, Whitney y COURTIVRON, Isabelle (eds.): op. cit., p. 278. 


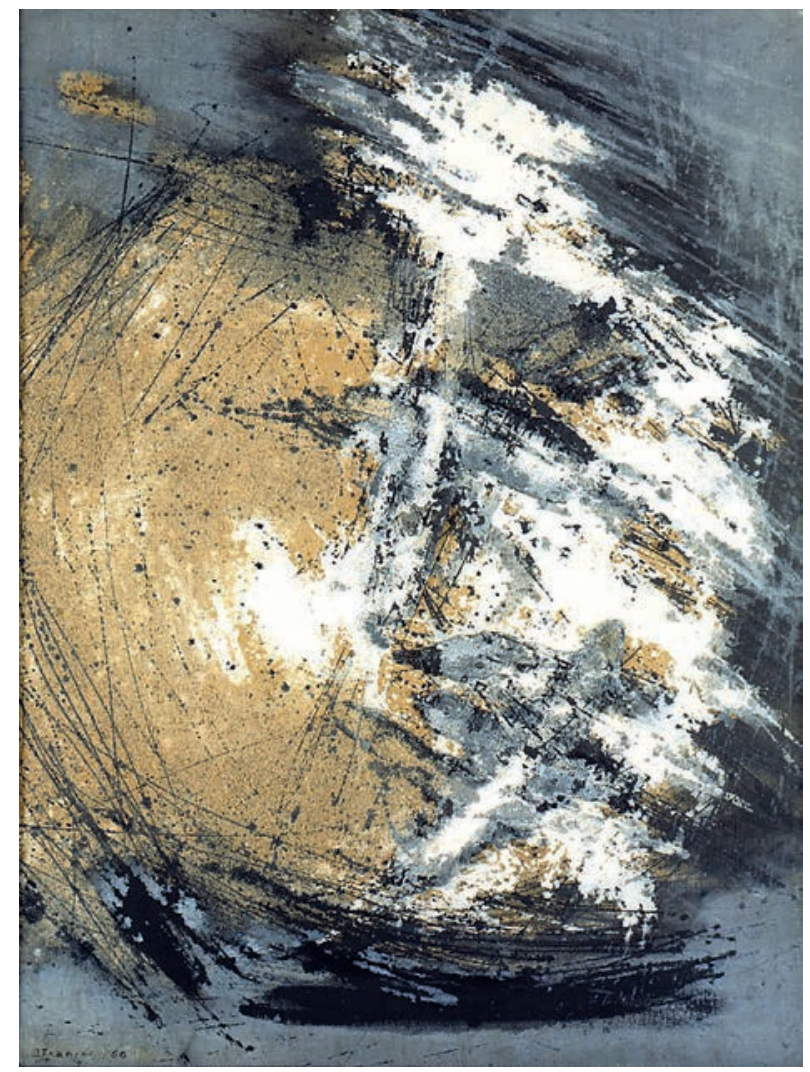

Fig. 2. Juana Francés. Composición n ${ }^{\circ}{ }^{52,} 1960$.

Por tanto, se abría la sospecha de que ella fuese aceptada condescendientemente en los círculos progresistas, no tanto por sus propios méritos, como por los de él. Esto es quizá lo que se esconde tras el episodio de la salida de Juana y Pablo del grupo El Paso a los pocos meses de su creación. Posiblemente chirriaba entre el resto de los integrantes del grupo el binomio mujer-vanguardia, como puede desprenderse de la narración que hizo Martín Chirino muchos años después:

[...] algunos tenían esa sensación de que Juana Francés no era una artista adecuada para ser miembro del grupo. Y ahí hubo una primera disensión, y a partir de eso de creó una especie de tensión y deciden que Juana no esté. Y entonces, claro, Pablo Serrano se sintió mal y abandonó el grupo.

Tan duro y humillante debió de ser para ella este episodio que en los años inmediatamente posteriores la propia artista parece querer eludir su participación en la creación de El Paso, de modo que en el texto de Cirilo Popovici sobre una 
exposición de la pintora realizada en el Ateneo de Madrid en 1959, no hay la más mínima alusión a esta etapa.

Este mismo crítico, que se declara amigo inseparable de la pareja, fue el encargado de realizar la pequeña monografía que publicó el Ministerio de Educación y Ciencia en 1976 sobre Juana Francés en la colección Artistas Españoles Contemporáneos $^{30}$. Tras presentar a la pintora y hablar sucintamente sobre su formación y sus vivencias artísticas juveniles, el crítico se plantea una difícil pregunta casi al comienzo de la obra: “¿Cómo eludir, abstraer, "depurar” esta biografía de la permanente presencia del escultor Serrano? Ello complica el trabajo, pero a mi me parece que toda biografía escrita sobre esta artista, debería ser complementada con otra de Pablo Serrano (y por supuesto, al revés)" 31 Tras esta pregunta que se hace el crítico podríamos hacer dos interpretaciones. La primera que Popovici se adelanta muchos años a Chadwick y Courtivron cuando se plantearon la necesidad de analizar las influencias que se producen en toda comunidad artística en una doble dirección, ya que "las intrincadas historias de ayuda y respeto mutuos, incluso en medio de los fracasos más dolorosos, emergen como uno de los aspectos innovadores de las relaciones (...)"32.

La segunda posibilidad es que el crítico se plantea simplemente una pregunta retórica, una elegante forma de destacar — sin usar el término influencia - el decisivo papel de Serrano como compañero de trayectoria artística de Francés, ya que parecería excesivo hablar de maestro o tutor, debido a la diferencia estilística y a la evolución de las obras de ambos.

A pesar de destacar la compenetración artística entre ambos, el crítico necesitaba poner a salvo la individualidad, tan esencial en la concepción occidental del arte:

Lo que es seguro es que pocas veces se ha dado en la historia del arte español tan total fusión por parte de una pareja de artistas y que a pesar de esa compenetración, se haya quedado cada uno con su identidad propia, insoslayable e indiscutible. Más de una idea pictórica o escultórica habrá salido de esta ósmosis estética, de esta convivencia que constituye la más auténtica ecología de un espacio artístico ${ }^{33}$.

Mientras la idea tradicional de individuo tocado por el genio permanecía inalterada, no podía por menos que mantenerse la jerarquía, ya que esta disolución, esta renuncia de la individualidad a favor de la pareja que elogiaba Popovici sólo se encuentra — voluntaria o forzadamente — en las mujeres. Dicho en palabras de

30. Juana Francés fue el sexto nombre femenino de la colección, y la monografía a ella dedicada llevaba el número 110 de la misma.

31. POPOPVICI, Cirilo: J. Francés. Madrid, Ministerio de Educación y Ciencia, 1976 , p. 11.

32. CHADWICK, Whitney y COURTIVRON, Isabelle (eds.): op. cit., p. 12.

33. POPOPVICI, Cirilo: J. Francés, pp. 11 y 12. 
Germaine Greer: "dada la insistencia de nuestra cultura en la creación solitaria, uno se interpreta siempre como importante, y el compañero es el otro". No es cuestión, por tanto, de escudriñar aquí la existencia de una mayor o menor colaboración y compenetración en el ámbito artístico en la pareja, sino de analizar cómo se interpreta ésta socialmente, en tanto en cuanto lo femenino se hace depender de lo masculino.

Una excepción en esta interpretación jerarquizada de la obra de Juana Francés respecto a Pablo Serrano es la que hizo Natalia Molinos en su tesis doctoral sobre la artista, en la que afirma que "la influencia que pudieron ejercer el uno sobre el otro es palpable, lógico en dos personas que vivían juntos y compartían durante un tiempo el taller de trabajo. La juventud de Juana, su interés por experimentar los caminos de la abstracción informal, creo que animaron también a explorarlos a un Pablo más asentado ya en su camino estético" ${ }^{34}$.

Lo que es altamente improbable es la situación que Popovici propone como de pasada en el texto citado más arriba: que se analice la obra de la mujer como elemento necesario para entender la del varón. Revisando las múltiples monografías dedicadas a la parte masculina de las parejas de artistas aquí tratadas, no se encontrará más información sobre las mujeres artistas que aquella que permita situar o sirva para reconstruir el "ambiente" del artista varón. En este caso, una vez revisada una buena parte de la bibliografía dedicada a Pablo Serrano, se confirma la sospecha de que la complementariedad generalmente es entendida como supeditación de la parte femenina; es decir que la obra de la mujer es incomprensible sin la sombra protectora, genial y "generadora" del varón, pero no al contrario.

De hecho, las referencias a Juana Francés en las biografías y estudios monográficos dedicados a Pablo Serrano no suelen sobrepasar unas líneas, y prácticamente nunca para poner en relación sus obras, ni hacer ningún tipo de propuesta sobre intereses, preocupaciones artísticas comunes o influencias mutuas. Julián Gallego, el autor de una monografía sobre Serrano ${ }^{35}$, no sólo no se plantea en ningún momento que esa biografía sobre el escultor debería ser complementada con otra sobre su compañera, la también artista Juana Francés, sino que no hay casi rastro de ella, como si no hubiera tenido ningún tipo de incidencia ni en la obra ni en la vida del escultor. Y no es que la trayectoria de la pareja en el momento de esta publicación fuera corta, pues llevaban quince años como pareja y en varias ocasiones ambos artistas habían expuesto juntos.

Hay que destacar, además que Juana cumplió respecto a Serrano el papel de introductora en el medio artístico español, ya que cuando la pareja se conoció el

34. MOLINOS, Natalia: La artista alicantina Juana Francés: estudio critico de su obra. Tesis Doctoral. Universidad de Alicante, 2010.

35. GALLEGO, Julián: Pablo Serrano. MEC (Dirección General de Bellas Artes), Colección Artistas Españoles Contemporáneos n. ${ }^{\circ}$ 8, 1971. 
escultor acababa de regresar de su larga estancia en Uruguay, como explica M. ${ }^{\mathrm{a}}$ Pilar Sancet: "Juana fue un gran apoyo para Pablo en todo momento, pero en sus inicios en España pudo ser, además, su introductora en el mundo artístico".

Aun así, los lugares comunes se repiten después de los años. En el catálogo de la exposición dedicada a dar a conocer la obra de Pablo Serrano fuera de nuestras fronteras que llevó a cabo SEACEX ${ }^{36}$ hay sólo unas leves menciones a Juana Francés, por una parte para indicar que fue pareja del escultor y, por otra, cuando se trata la breve pertenencia de ambos al grupo El Paso.

A pesar de todo Juana Francés logró un mayor reconocimiento profesional que muchas otras pintoras de la época, especialmente aquellas que se movieron en la vanguardia abstracta. El hecho de no haber tenido hijos no resulta un factor indiferente a la dedicación total de la pintora a su proyecto artístico.

El caso de Juana Francés, con una diferencia de edad respecto a Pablo Serrano que le obligó a mantenerse en guardia para que la figura de su compañero sentimental no fuese vista como la del mentor o tutor artístico, no fue habitual en la plástica española de las décadas de los 40 y los 50. Lo más habitual era que los lazos sentimentales en las parejas de artistas naciesen en el periodo de formación de ambos, cuando ambos eran jóvenes aprendices en talleres y academias de Bellas Artes. Este fue el caso de las cuatro parejas formadas en la década de 1950 por los pintores Amalia Avia y Lucio Muñoz, María Moreno y Antonio López, Isabel Quintanilla y el escultor Francisco López Hernández, ó Esperanza Parada y el también escultor Julio López Hernández. La mayor parte de este grupo — con la excepción de Lucio Muñoz que pronto investigó en los caminos de la abstracción informalista - se orientó hacia una pintura figurativa que mayoritariamente se incluyó en lo que se ha denominado el Realismo Madrileño. La presencia de las mujeres en este grupo no fue importante sólo por su número sino porque:

[...] constituían la primera generación de profesionales de la pintura en la España contemporánea aunque hubieran ya existido pintoras al margen de cualquier grupo generacional propiamente dicho (...) No sólo fue esa la primera generación en que hubo una cierta paridad entre el componente masculino y femenino (los casos de Maruja Mallo y de Menchu Gal, en el preguerra y en la posguerra constituyen una excepción a lo habitual en su época), sino que fue también la primera vez que se produjo el matrimonio entre compañeros en las tareas artísticas" ${ }^{\text {37. }}$.

36. VV. AA. Catálogo de la Exposición Pablo Serrano, Edita Ministerio de Asuntos Exteriores. Dirección General de Relaciones Culturales y Científicas/ Sociedad Estatal para la Acción Cultural Exterior (SEACEX)/ Gobierno de Aragón. Departamento de Cultura y Turismo, 2003.

37. TUSELL, Javier: “Compañeros en Madrid: Anatomía de un grupo generacional”. E VV. AA.: Otra realidad. Compañeros en Madrid. Madrid, Caja Madrid, Fundación Humanismo y Democracia, 1992, p. 89. 
Nacidos todos ellos en torno a la guerra civil, hay una relación generacional que constituye mucho más que una coincidencia cronológica, ya que generó una mirada similar hacia el mundo, así como cierta coincidencia en los planteamientos estéticos. Esa mirada se dirigía hacia lo cercano, lo íntimo, se refiriese al espacio privado o a los rincones urbanos. Era todo aquello que parecía ajustarse más a lo que se ha venido considerando tradicionalmente los ámbitos de la feminidad, en los espacios que se circunscriben a lo domestico, lo intrascendente, espacios heredados de aquellos que décadas antes habían sido el centro de interés de las pintoras impresionistas.

Sin embargo, no fueron las mujeres artistas de este grupo las que consiguieron que la corriente del Realismo Madrileño despertase el interés de la crítica como una producción contemporánea y no como un residuo del pasado tras el triunfo de la abstracción en la década de $1950^{38}$. Es significativo que el Realismo se vio positivamente sancionado a partir de la obra de un varón que apostó por este camino: Antonio López. Fue el quien les justificó, convirtiéndose en una tabla de salvación para los y las artistas que se adscribían a este tipo de figuración. Así lo reconoce Amalia Avia en sus memorias:

En pleno auge de la abstracción, la aparición de Antoñito y su talento pronto reconocido dignificaron y pusieron al día la pintura realista y hasta la situaron en vanguardia justo en el momento de esplendor de lo abstracto, cuando el realismo era considerado reaccionario y académico (...) El fenómeno Antoñito ha hecho que se valoren y consideren pinturas figurativas, aún las más distintas a las suyas como pueden ser las de Carmen Laffon o las mías ${ }^{39}$.

Las memorias de Avia constituyen una fuente básica para este tema, ya que están trufadas de comentarios y recuerdos en las que se mezclan lo personal y lo profesional. En este texto la pintora va desgranando sus recuerdos sobre el ambiente y las relaciones de los años de formación en la Escuela de Bellas Artes de San Fernando, en los que el grupo de condiscípulos se convirtió en grupo de amigos y se crearon las parejas que finalmente concluirían en matrimonios. Recuerda Amalia cómo en los debates artísticos que se generaban en el grupo, ellos — los

38. "Este grupo, compuesto por figuras de la talla de Antonio López, los hermanos Julio y Francisco López Hernández, Isabel Quintanilla, Amalia Avia, y otros, no ha recibido mucho espacio en los medios de comunicación y, sin embargo, sí ha tenido un reconocimiento artístico, también internacional discutido por pocos. El público de nuestro país reconoce a alguno de estos artistas, sobre todo a Antonio López, pero ese conocimiento no se lo debe, por ejemplo, a la lectura de la prensa diaria, preocupada en exceso por la presencia en sus páginas de otros artistas en y para los medios". DOMÍNGUEZ, Susana: "Relaciones entre el arte y la información. El caso del realismo madrileño". Revista Latina de Comunicación Social, 21 (septiembre de 1999).

39. AVIA, Amalia: op. cit., pp. 237-238. 
varones - dejaban ya muy claro a quien le correspondía el papel de la genialidad, la innovación y, por tanto, el éxito:

Estos insolentes amigos míos me hacían ver en sus conversaciones que el arte era para muy pocos; hablaban como si sólo unos cuantos elegidos, entre los que, por supuesto, no se hallaban las mujeres, tuvieran acceso a la creación. Estaban tan seguros, pisaban tan fuerte en materia artística, que ahora al recordarlo me parece raro que no tuvieran todavía una obra hecha, una obra que justificara tanta insolencia y seguridad. Acababan de salir de la escuela y ya los mirábamos como genios, quizá porque ellos mismos así se miraban ${ }^{40}$.

Este texto contrasta con la actitud que las artistas solían tener al hablar de su obra en aquellos momentos, mucho más cautelosa y modesta, quizá porque todo a su alrededor les estuviese enviando el mensaje de que pintar, no era lo mismo que "ser artista", porque para ello es preciso abrir nuevos caminos, adentrarse en la genialidad, y eso es lo que no se consideraba al alcance de las mujeres. Aquí, posiblemente resida la perplejidad que refleja Avia ante el reconocimiento que consiguió con alguno de sus cuadros:

Hubo un cuadro, el de unos emigrantes cargados de maletas por un andén de estación, que fue especialmente reproducido, en alguna ocasión en páginas artísticas. Hablaban mucho de lo insólito y hasta de lo atrevido de los temas; a mi me sorprendía, pues yo encontraba de lo más normal pintar esas cosas y pensaba que a cualquiera se le podían ocurrir porque allí estaban.

La falta de autoestima en que eran educadas todas las mujeres ${ }^{41}$, también las que aspiraban a ser artistas, explica que la puerta del éxito del Realismo Madrileño, su reconocimiento, necesariamente fuese abierta por un varón, Antonio López. Y también por ello es constante la comparación de la obra de las pintoras que formaron parte del grupo con la de sus respectivos esposos y compañeros. Buen ejemplo de ello puede ser un texto en el que se destaca que en el trabajo de Amalia Avia y su marido, Lucio Muñoz, hay una "ósmosis admirable que no sólo a ninguno de los dos estorba sino enriquece". Pero lo cierto es que la mencionada ósmosis sólo se cita cuando se analiza de la obra de Amalia Avia, pero no hay ninguna referencia a ella en las muchas monografías dedicadas a Lucio Muñoz.

Además, generalmente la comparación de la obra de la mujer con la del hombre conlleva una minusvaloración de la primera, planteada siempre de un modo sutil a base de destacar los rasgos asociados a la feminidad tradicional, como la

40. AVIA, Amalia: op. cit., p. 207.

41. Germaine Greer habla en 1979 del "ego dañado" que afecta a las mujeres en su libro La carrera de obstáculos. 


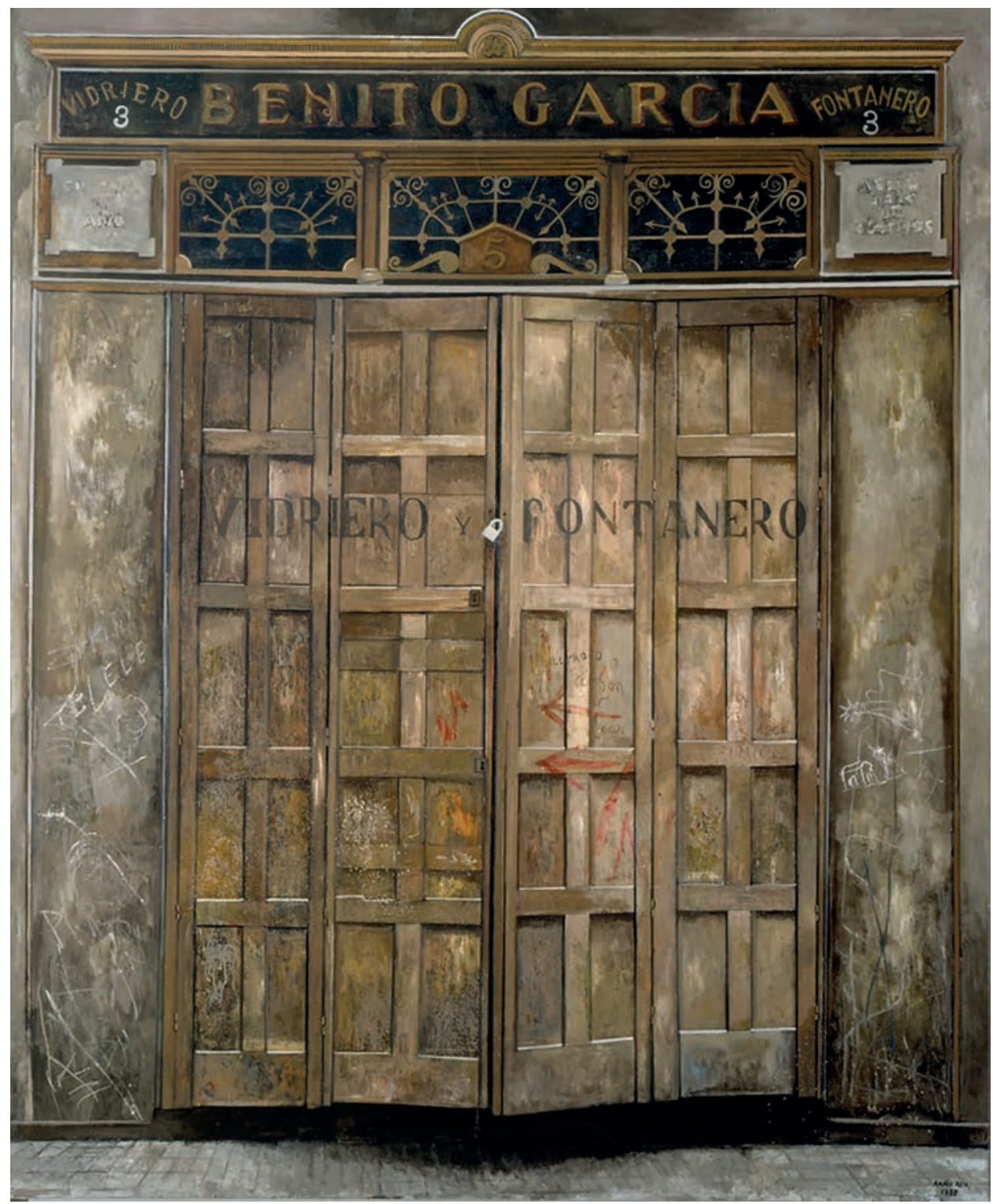

Fig. 3. Amalia Avia. Benito García, Fontanero. 1988.

delicadeza o su relación con la ética de cuidados. Valores y ámbitos considerados "segundos" en nuestra sociedad, por haber estado atribuidos tradicionalmente a las mujeres. En ese sentido llama la atención el modo en que se fuerzan los argumentos por parte de los críticos, como se refleja en el siguiente texto de Adolfo Castaño: 
Amalia Avia acentúa mucho su presencia en lo que hace, la marca de su femenina condición, no en la forma que tiene y muestra fortaleza, sino en la sugerencia constante de su estar presente, como una madre, en lo familiar de la forma, en lo gastado en lo convivido de ella (...)

Una vez que el cuadro está fuera del estudio, Amalia Avia mantiene, desde lejos con él una relación maternal. Como si fuera uno de sus hijos que jugara en la plaza, y ella, desde el balcón de su mirada y su mano le dará la seguridad necesaria en el peligro del juego.

Esta situación se repite en el caso de la pintora María Moreno, cuya obra se mide permanentemente con respecto a la obra de Antonio López, su esposo y gran referente del realismo español. Como muestra de ello sirve el texto que sigue, tomado de una monografía dedicada a este pintor:

María Moreno, esposa de Antonio López desde 1961, representa una realidad onírica, donde la luz y el color predominan sobre las formas. Su pintura muchas veces da la sensación de estar realizada como un consuelo personal, con una enorme capacidad de trasmitir unos valores por encima de lo terrenal. En este sentido se puede hablar de una pintura generosa hacia los demás, algo que en muy pocas ocasiones ocurre ${ }^{42}$.

El conjunto del texto lleva implícita la idea de la comparación, destacándose de la obra de María no sólo aquellos valores plásticos más relacionadas con lo sentimental y onírico, sino una intencionalidad espiritual y moral al suponerla basada en "un consuelo personal" y "generosa hacia los demás". Una valoración que se ajusta bien a los estereotipos que aún perviven sobre la propia feminidad $\mathrm{y}$, en consecuencia, de las obras de las mujeres.

En este libro, dedicado a Antonio López, se compara también la obra del artista con la de la pintora Isabel Quintanilla, ya que — se dice — sus carreras "se han desarrollado en paralelo" dentro de la corriente figurativa. Tras explicar que ambas obras coinciden en "las temáticas elegidas y el modo de plasmarlos en el lienzo", el autor sigue diciendo: "La pintora también escoge como temas los bodegones, las flores, los interiores o las ventanas, temas tratados por Antonio López". Con ese simple "también" que introduce el autor, es evidente que es "ella" la que le sigue a él. El hombre es el pionero y ella la seguidora.

En este mismo sentido cabe citar otros dos ejemplos. El primero está extraído de una crítica escrita por Isabel Cajide en 1962 sobre la pintura de Amalia Avia:

Amalia Avia ha pintado como un "maestro" esa realidad de cada día; ha pintado sin enriquecerlas más que con amor, las cosas cotidianas a la mayoría,

42. MIRANDA, Samuel y FERNÁNDEZ-CID, Miguel: Antonio López. Barcelona, Ciro Editores, 2006, p. 9. 
las cosas simples, asequibles, las cosas populares (...) Ha logrado introducir al espectador un clima humano y poético que trasciende y se comunica, que conmueve de puro limpio ${ }^{43}$.

A renglón seguido de utilizar el término de "maestro" para elevar de categoría la pintura de Amalia, la crítica pasa a hablar de los temas que trata utilizando términos valorativos que inciden sobre los sentimientos de amor y el "clima humano y poético". El segundo ejemplo corresponde a una publicación del año 2000 que hace un repaso de la pintura española, en la que se dedica únicamente un párrafo a las pintoras del Realismo Madrileño y lo hace del modo que se asemeja mucho a lo escrito casi treinta años antes:

Tres mujeres se mueven en Madrid en el ámbito del realismo: María Moreno, Isabel Quintanilla y Amalia Avia; atentas a la realidad cotidiana en distintas vertientes - urbana en el caso de Avia, íntima y silenciosa en el de Moreno, cercana Antonio López, doméstica y pulcra en el de Quintanilla- $(\ldots)^{44}$.

Íntima, silenciosa, doméstica, pulcra...estos son adjetivos que pocas veces encontramos referidos a las obras de los varones del mismo grupo y que poco se ajustan a lo que se pide del Genio, aún a finales del siglo XX y comienzos del XXI.

La invisibilidad de las artistas tras sus parejas se trasluce aún en un artículo periodístico realizado con motivo de la celebración en el año 1996 de una exposición en torno a los realistas españoles en la Galería Marlborough de Londres, un evento que conmemoraba otra exposición realizada con los mismos nombres 23 años antes. El periodista nos sitúa del modo siguiente en el lugar donde va a realizar la entrevista al conjunto de pintores, pintoras y escultores que participaran en la exposición ${ }^{45}$.

La casa de Antonio López, autor de alacenas, flores y una cacharrería casi zurbaranesca, fue el lugar elegido por este periódico el pasado lunes para hablar de la exposición con algunos de sus protagonistas, con aquellos que todavía no habían partido hacia Londres. La pintora María Moreno, mujer de Antonio, era la única que se encontraba en casa a la hora fijada.

Llama la atención que después de situar al lector en "la casa de Antonio López", dedique una larga frase a describir los temas de su pintura, para finaliza el párrafo diciendo que le recibe María Moreno, una de las pintoras protagonistas del evento, que lógicamente se encontraba allí a la hora fijada. Y digo lógicamente

43. CAJIDE, Isabel: "La pintura de Amalia Avia: el mundo que nos rodea". Artes 62, 1964.

44. AA. VV.: La Pintura española. La Edad Moderna. De Goya a nuestros días. Barcelona, Carroggio, 2000, pp. 66-67.

45. Diario El Mundo Miércoles, 19 de junio de 1996. 


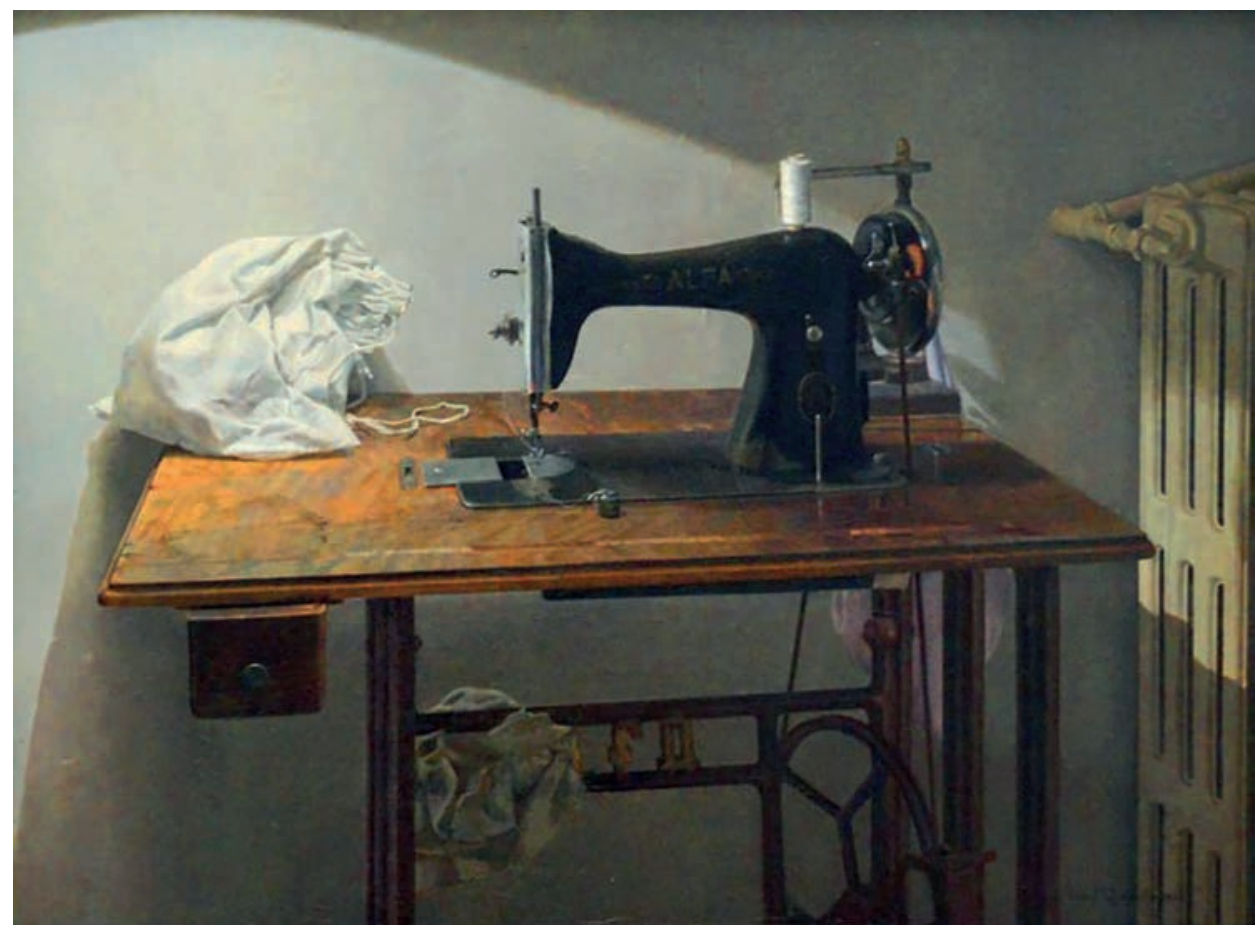

Fig. 4: Isabel Quintanilla. Homenaje A Mi Madre. 1971.

porque el periodista no parece darse cuenta de que además de la casa de Antonio López era también la casa de María Moreno.

Además el diferente interés mostrado por la crítica y de la academia ante la obra de unos y otras, el distinto valor social y económico atribuido a las obras de cada uno de los miembros de la pareja, situaba a las pintoras ante la necesidad de comparar constantemente su producción y la de sus respectivos compañeros sentimentales o maridos. En este sentido las memorias de Amalia Avia vuelven a ser fuente esencial. Hay un párrafo en el que la pintora cuenta cómo a finales de la década de 1970 la galería Juana Mordó organizó en Basilea una exposición conjunta de su obra y la de Lucio, aunque expuesta en espacios separados, cosa que, cuenta la pintora, "a Lucio, supongo no le hizo ninguna gracia; bueno no lo supongo, estoy segura. El pobre se aguantó y la cosa no fue mal: los stands fueron muy visitados"46. Aunque hayan sido habituales estas exposiciones dobles en toda la historia de las parejas artísticas, lo que subyace en gran parte de los casos es

46. AVIA, Amalia: op. cit., p. 338. 
que son consideradas como exposiciones "menores" por el hombre, una especie de concesión sentimental a la que no se puede negar.

El deseo de no ver su obra comparada constantemente con la de su marido y de tener su propio espacio llevó igualmente a Amalia a dejar la galería Juana Mordó, en un intento de evitar ser vista como un elemento secundario. Por ello regresó a su antigua galería (Biosca) según cuenta la pintora: "yo no quería ser pintora consorte y estando los dos en el mismo sitio era inevitable" 47 .

El término de "pintora consorte" vuelve a aparecer en otras ocasiones en las Memorias de Avia, poniendo de manifiesto el lastre que ello implicaba, no sólo para ella, sino para las artistas de su generación que compartieron la vida con sus maridos artistas. En las pocas ocasiones en las que el modelo clásico del éxito masculino - ventas, visitantes, reconocimiento - se invertía y éste le correspondía a la artista se produce un extrañamiento en la pintora, a la vez que un cierto regocijo:

En una ocasión, coincidió en Barcelona una exposición de Lucio con una mía en dos galerías muy cercanas. Yo vendía casi toda la exposición y el muy poco. (...) Al pasar Lucio a visitarla desde la suya, hubo al menos dos personas que le preguntaron: “¿usted también pinta?", pregunta que me habían hecho a mí en numerosísimas ocasiones a lo largo de mi carrera como pintora consorte. Por fin era yo la pintora y él el posible aficionado o poco más. ¡Qué alegría me dio! Se lo conté a todo el mundo ${ }^{48}$.

Desde mediados de la década de 1970 el éxito comenzó a llegar para Amalia - un éxito tardío como ella misma dice en sus memorias - por lo que sus cuadros no sólo se vendían, sino que eran demandados para exposiciones en instituciones y galerías privadas.

Aun siendo consciente de que las obras de Lucio Muñoz y las suyas eran muy diferentes, se detecta en la narración de Amalia Avia la necesidad de compararse y el sentimiento íntimo de que su pintura estaba por debajo de la de su marido. $\mathrm{Al}$ escribir sobre los miedos y dudas lógicas que le asaltaban ante su primera exposición, la pintora comparaba de este modo su obra, no sólo con la pintura informalista que a finales de la década de 1950 atraía el interés de una parte de la crítica, sino específicamente con la de quien era entonces su pareja y poco después su marido, Lucio Muñoz:

[...] yo temía que mi pintura no le gustara ${ }^{49}$ : no era nueva, no era abstracta, no había ninguna innovación como materia y estaba pintada con pincel y óleo so-

47. AVIA, Amalia: op. cit., p. 310.

48. AVIA, Amalia: op. cit., pp. 337-8.

49. Se refiere al crítico José de Castro Arines a quien pidió que le hiciera la presentación para el catálogo. 
bre lienzo o tablex; se trataba de una pintura humilde y sencilla que pretendía parecerse lo más posible al modelo elegido.

En ese sentido resulta curioso que Amalia se identifique más con la forma de sentir y hacer arte "de cualquier abstracto que de Antonio", refiriéndose a Antonio López. Parece claro por el uso del colorido, de los ecos del paso del tiempo sobre la materia gastada, vivida, que aunque no cite a Lucio en este párrafo, es fundamentalmente a su pintura a la que Amalia se refiere cuando escribe "cualquier abstracto". Y si esto parece lógico, dados las años de convivencia que suponen un intercambio de experiencias y visiones entre ambos, cabe que nos detengamos a pensar por qué ni Lucio Muñoz ni de ninguno de los artistas que formaron parte de estas parejas dejaron por escrito ninguna frase de reconocimiento de la comunidad de intereses artísticos que les unía como iguales con sus compañeras de vida y creación.

Quizá porque en ese momento la situación tenía difícil salida sin pasar por la ruptura y la renuncia a muchas cosas, las artistas tuvieron que cerrar los ojos y mantener una obligada generosidad, desechando sentimientos tan habituales en el mundo del arte como la envidia profesional. En palabras de Amalia Avia, "la envidia, que suele estropear todas las relaciones, no es fácil que se de en el matrimonio (...) cuando dos personas comparten su vida sienten recíprocamente las penas y alegrías de ambos como propias" ${ }^{50}$.

En definitiva, no era difícil reconocer que, tras la solidaridad y la comunidad creadora que se generaba en la pareja de artistas, solía darse una evidente cesión por la parte femenina, ya que se ha venido considerando que debía ser más generosa "por mandato de la naturaleza".

En definitiva, aunque de manera natural pudo haber - seguro que los huboconsejos y apoyos mutuos en el proyecto creativo de ambos miembros de la pareja ${ }^{51}$, los logros y renuncias a dicho proyecto por parte de ambos fue asimétrica, pues para apoyar al esposo o amante ellas generalmente se vieron obligadas a postergar o supeditar su propio proyecto artístico. Además de la gestión de lo doméstico y el cuidado de la descendencia, ellas ejercieron como apoyo moral y material en los períodos difíciles. Fueron ayudantes para todo, fieles acompañantes en los viajes y exposiciones, así como divulgadoras de la obra de su esposo y/o compañero. Buen ejemplo de esto último es el papel de Elvireta Escobio en la difusión de la obra de Millares que anteriormente se ha analizado, o el hecho de que Maria Moreno actuara como productora de la película El Sol del Membrillo, en la que

50. AVIA, Amalia: op. cit., p. 228.

51. Amalia Avia recuerda, por ejemplo, que Lucio Muñoz le aconsejaba que no dijera que ella pintaba con cierta rapidez sus obras, porque eso no correspondía con la pintura realista en que se pinta poco y despacio por ser una pintura minuciosa. 
el director Víctor Erice pretendió convertir a la cámara en testigo silencioso del hacer cotidiano de la pintura realista.

En esta historia de comunidad de proyectos creativos en pareja y de renuncias por parte de las creadoras plásticas, cabe tratar también la trayectoria de la pintora barcelonesa Magda Bolumar, casada con el escultor Moisés Villèlia. Ambos artistas se movieron en los círculos del Informalismo catalán, aunque sólo la obra de Moisés llegó a tener reconocimiento artístico.

Magda nació en el año 1936 en Caldas de Estrach (Barcelona), trasladándose la familia a Mataró tres años más tarde. En 1948 comenzó a asistir a clases particulares en el estudio del pintor Rafael Estrany, quien se había formado con el pintor belga James Ensor y que por aquellos años era director del Museo Municipal de Mataró. En 1952 Magda comenzó sus estudios en la Escuela de Artes y Oficios de Mataró mientras seguía asistiendo al taller de Estrany.

A mediados de la década de 1950 Magda entró en contacto con miembros del grupo Dau al Set y con Moisés Villélia, que fue miembro fundamental del grupo Arte Actual y que se convertiría en su esposo en el año 1958, coincidiendo con un periodo de intensa experimentación por parte del escultor ${ }^{52}$. La pareja, tras un periodo lleno de dificultades económicas en Mataró ${ }^{53}$, se traslada a Cambrils. Allí, a finales de la década de 1950 la pintora, tras dejar atrás la figuración, comienza a experimentar realizando cuadros con arpilleras que tiñe de color y transforma con la aguja y el punzón; son las obras que en los años siguientes serán conocidas como las Xarpelleres de Magda. Estas obras fueron realizadas paralelamente a los Homúnculos de Manolo Millares y las obras en tela de alambre recosida de Rivera, aunque están desprovistas de su sentido trágico y tienen un mayor componente constructivo. En el año 1960 Magda Bolumar inaugura una exposición individual, aún con obra figurativa, en el Museo Municipal de Mataró y es también el año en que presenta sus Xarpelleres en la Sala Gaspar, la más avanzada galería de Barcelona en la que tenían lugar las actividades del Club 4954. La presentación de esta obra la realiza Cirici Pellicer.

52. Así describe $\mathrm{M}^{\mathrm{a}}{ }^{\mathrm{a}}$ Lluïsa Borràs a Magda: "A raíz de la exposición de febrero ha conocido una muchacha de Mataró, dulce, callada, interesante y sensible, que trabaja con el pintor Estrany a la vez que acude a la Escuela de Artes y Oficios. Es Magda Bolumar, que se convertirá dos años después en su esposa". BORRÁS, M. ${ }^{a}$ Lluïsa: Villèlia, Ediciones Polígrafa, 1974, p. 123.

53. Cirici Pellicer cuenta que el nuevo matrimonio vivía en una buhardilla de una habitación, "Dormían en una cama sin sábanas y hacían su comida en un fogón de tierra portátil, que ahumaba techo y paredes. Los niños de la calle les tomaban por gitanos y les echaban piedras. Ellos solían andar muy abrazados uno al otro por las calles de Mataró". Cita tomada de BORRÁS, M. ${ }^{a}$ Lluïsa: op. cit., p. 127.

54. Las actividades del Club 49 actividades se orientaba a la difusión de grandes artistas del siglo XX, así como a la promoción de los jóvenes artistas de la vanguardia catalana. 


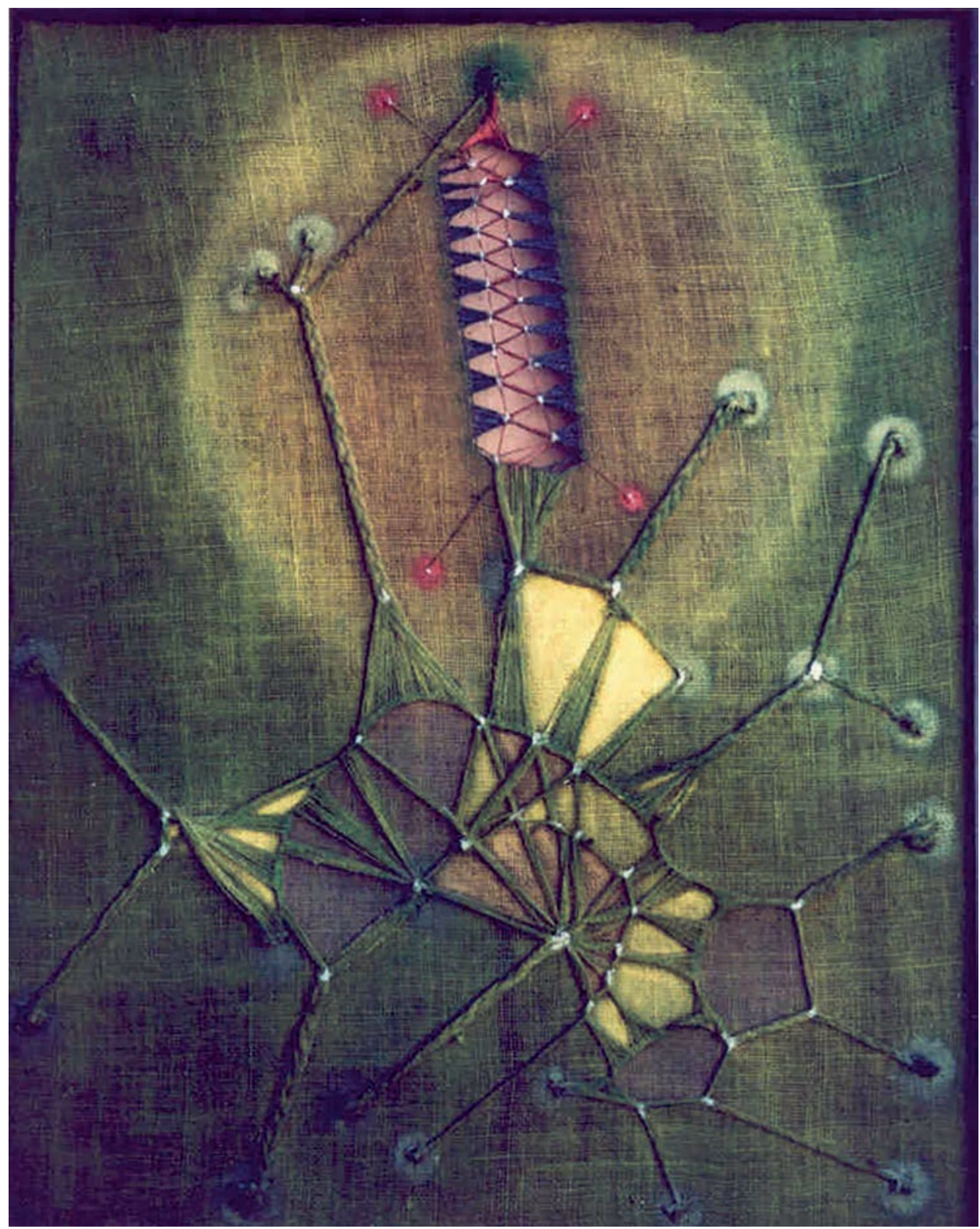

Fig. 5. Magda Bolumar. Xarpellera. (Colección particular). 
La década de 1960 es para Magda decisiva, pues recibe premios ${ }^{55}$, realiza exposiciones individuales y colectivas, como la que bajo el título $O$ Figura buscaba hacer un homenaje a Velazquez ${ }^{56}$, siendo un momento de efervescencia investigadora y en el que desarrolla proyectos varios con Moisés Villèlia, buen ejemplo de los cuales son la creación de las firmas Sur-Bo, dedicada a la artesanía de la estampación, o Burenc de diseño industrial. Otros proyectos realizados en colaboración por la pareja fueron los desarrollados en torno a la jardinería, destacando entre ellos el Jardín Pros, de inspiración oriental.

En esta década Magda y Moisés, junto con otros representantes de la cultura catalana como Joan Brossa o Antoni Tapies, van a participar en el proyecto de la revista Inquietud ${ }^{57}$ de Vic, dirigida por Bonaventura Selva y fundada por un grupo de jóvenes ${ }^{58}$ con la intención de informar de las nuevas corrientes del arte y la literatura que se desarrollaban fueras y dentro de las fronteras del estado español. La revista comenzó a publicarse en 1955 y pervivió hasta 1966, incidiendo especialmente en las interrelaciones que se establecían entre las diferentes manifestaciones artísticas. Magda Bolumar realizó dos portadas de la revista, una en el año 1961 y otra en el último número, correspondiente a septiembre de 1966, pero además en el año anterior se publicaba en la revista un poema de Joan Brossa con el título Dos quadres de Magda Bolumar.

En 1967 una beca concedida por el Instituto Francés lleva a los Villèlia a París, donde residirán, junto con su hijo Nahum, durante año y medio. En París Magda ensaya con otros materiales, como la rafia, para la realización de sus obras. A su regreso y tras unos meses en Barcelona, Moisés Villèlia marcha Latinoamérica. Después de una breve estancia en Argentina, Moisés se instala en Ecuador, hacia donde unos meses después salen Magda y el hijo de ambos.

En Ecuador sus investigaciones plásticas se combinan con el interés por el arte llamado "primitivo" y los temas antropológicos, al entrar en contacto con la cultura de los indios Tolita que floreció en Esmeralda 150 años a.C. Moisés y Magda investigaron sobre el significado y el valor plástico de algunas piezas de esta cultura, descubriendo el significado de los llamados sellos "Quitu-cara".

A finales de 1971 Magda regresó con su hijo Nahum a Barcelona y poco después les siguió Moisés. La familia se instaló en el Molló, un pequeño núcleo en el Pirineo, en una finca llamada Can Dilluire, en la que crearon un paisaje a medida para su vida y su arte. Allí Moisés siguió realizando escultura, mientras Magda

55. En 1960 recibió la mención de honor del II Premio Granollers de Pintura.

56. En este homenaje "informal” a Velázquez, como lo definía el crítico Santos Torroella en el catálogo, exponen entre otros Rafael Canogar, Martín Chirino, Luís Feito, Ángel Ferrant, Juana Francés, Cesar Manrique, Manuel Millares o Lucio Muñoz.

57. En 1959, por imposición legal, pasaría a llamarse Inquietud Artística.

58. Josep Brugalla, Rosa Tena, Jaume Clotet, Joan Furriols y Josep M. Selva, aunque este murió antes de llevarse a cabo el proyecto. 
seguía con su pintura y trabajaba también en la realización de piezas de esmaltes. Durante la década de 1970 no hay apenas presencia pública de su obra pues no participa en más exposiciones que una realizada en la Sala Gaspar (1970) y otra realizada en 1972 en la Galería Wilson Hallo de Quito (Ecuador). La hipótesis sobre las causas de la "desaparición" del panorama artístico de Magda Bolmar en estos años es fácil, dada la coincidencia con la infancia de su hijo y que fue una etapa de reconocimiento público de la obra de su marido.

En las siguientes décadas las obras de Magda, que ha seguido produciendo de un modo silencioso sus Xarpelleres, dibujos y esmaltes cada vez más cargados de lirismo, vuelven a verse en las salas de exposiciones, pero las demandas del mercado artístico van por caminos muy distintos en esos años.

Hoy se encuentran algunos datos sueltos que ofrecen sólo indicios sobre la obra de esta artista. Por ello, como en casos anteriores, se hace necesario rastrear su presencia en los estudios publicados sobre su marido. $Y$ en este rastreo vuelven a aparecer las referencias a la generosidad natural de la mujer en la pareja artística. Así, en el estudio que dedica M. ${ }^{a}$ Lluïsa Borràs a Moisés Villèlia, describe del siguiente modo la actitud de Magda Bolumar, al referirse a las investigaciones plásticas llevadas a cabo la pintora a finales de la década de 1950: "siempre dejando la obra propia en segundo término, fascinada por el arte y la personalidad de Moisés. Pocas veces se habrá dado una compenetración mayor entre dos seres ni una mayor semejanza de carácter (...)"59. Aquí se pone de manifiesto cómo, sin subterfugios de ninguna clase, lo que se denomina en ocasiones "complementariedad" ha sido en la mayoría de las ocasiones "supeditación", ya que el mandato de género suponía como "natural" en las mujeres artistas ese papel segundo aún a mediados de la década de 1970, cuando se escribió este texto. La autora del estudio monográfico dedicado Moisés Villèlia, buscando sintetizar una frase esta intima unión artística entre la pareja, escribe que Magda Bolumar era "una especie de doble suyo en femenino". Una frase que en realidad invisibiliza a la artista al negarle su propia trayectoria y personalidad, convirtiéndola en alter ego de Villèlia.

Sin embargo, una mirada a la pintura de Magda Bolumar nos permite de inmediato reconocer una obra personal. Es la obra de una artista que experimentó de un modo totalmente original con nuevos materiales, como por aquellos años lo hicieron los artistas de El Paso o Tapies; fue también una artista que se interesó y participó en proyectos relacionados con la integración de las artes. En definitiva, una artista que formó parte plenamente de los colectivos de vanguardia que en unos años difíciles introdujeron oxígeno en la plástica del estado español. Su obra se encuentra en la actualidad en colecciones públicas como la del Museo de Granollers y la de la Fundación la Caixa. 
Tanto en el caso de Magda Bolumar, como en el de Juana Francés y el resto de pintoras tratadas en este apartado podría finalizarse con la idea de que la sombra del gran árbol, es decir la parte masculina de estas parejas, al proyectarse sobre sus respectivas compañeras, impidió o dificultó que ellas lograran construirse una trayectoria autónoma tal como se exige a todo/a artista.

Podríamos citar otros nombres, otras parejas de artistas o en las que ambos se movieron dentro de los círculos artísticos durante estos años ${ }^{60}$ y veríamos que la historia se repite más allá del período franquista: un mayor éxito y reconocimiento social para ellos y un papel subsidiario para ellas, al margen de su valía artística. Los condicionamientos a que se vieron sometidos todos ellos en el periodo franquista explican en gran parte esta situación.

Sin embargo, la llegada de la democracia y la igualdad formal entre mujeres y hombres no supusieron la normalización automática de la situación de las mujeres en el arte español, manteniéndose la "anomalía" que acabamos de analizar y que lógicamente ha dejado señales en el mundo del arte en la actualidad.

Si bien es cierto que las generaciones de mujeres que comenzaron a desarrollar su obra en democracia han vivido una realidad bien distinta, en el caso de las parejas de artistas la asignación del papel subsidiario a las mujeres no ha desaparecido del todo, debido fundamentalmente a los sesgos androcéntricos insertos en el imaginario de buena parte del sistema artístico y de la academia. Un buen ejemplo es el caso de la pintora Patricia Gadea, cuya obra algunos críticos han querido minimizar ante la de Juan Ugalde, con quien estuvo casada y junto con el que fundó en la década de 1980 el grupo Estrujenbank ${ }^{61}$, uno de los colectivos artísticos más importantes de las últimas décadas del siglo XX en España.

Nacida durante la etapa del desarrollismo, Patricia inició sus estudios de Bellas Artes en 1979 y junto con su marido —el también pintor Juan Ugalde- fue una de las figuras más señeras de la denominada Generación de los 80 . Ambos, acompañados de otros artistas, llevaron a cabo interesantes proyectos colectivos como la creación de una supuesta galería denominada Mary Boom ${ }^{62}$ (1985) en un pasaje subterráneo de Madrid o la del colectivo Estrujenbank, en el contexto del cual publicaron el opúsculo Los tigres se perfuman con dinamita ya a comienzos de la década de los 90. En este texto patricia Gadea tuvo un papel significativo, como destaca el artista Dionisio Cañas: "con Estrujenbank publicaron un libro, Los tigres se perfuman con dinamita, donde aparecen algunos textos de Gadea" ${ }^{3}$. El grupo

60. Ana Peters y Tomás Llorens, Maria Girona y Rafols Casamada, etc.

61. Estrujenbank se fundó en Madrid en 1989 por los artistas Patricia Gadea, Juan Ugalde, Mariano Lozano y el poeta Dionisio Cañas.

62. Pretendían evocar a una mítica sala neoyorkina de ese mismo nombre.

63. CAÑAS, Dionisio: "Patricia Gadea, la oscura luz de una pintora" http://www.elmundo. es/elmundo/2006/04/20/obituarios/1145525683.html (consultado el 7 de julio de 2014). 
creó también una sala de arte con una visión alternativa a la oficial y comercial ${ }^{64}$, que se convirtió en un referente del arte de los 90 y expuso colectivamente en las ediciones de ARCO de 1990 y 1991 y en varias galerías privadas.

Sin embargo, la necesidad de ajustar la realidad al modelo tradicional y un punto heroico de autoría (que por cierto es más rentable para el arte comercial) hizo que pronto Estrujenbank se identificase cada vez más como obra de Ugalde. Esto se vio ya en el catálogo de una exposición que se llevó a cabo a finales de 1989 en la sala Buades de Madrid, en el que se atribuye exclusivamente a Juan Ugalde la autoría de las obras que correspondían al conjunto grupo. Consecuencia de ello es que aún hoy "muchos siguen hablando como si la exposición fuera sólo de Juan" 65 .

En este contexto situar la obra de Patricia Gadea en un segundo plano era casi una consecuencia natural en la relectura de los hechos que los críticos e historiadores han realizado al tratar sobre este período y sobre el grupo. Así en un libro que analiza las nuevas tendencias de la pintura española, publicado en 2006, puede leerse:

Entre 1986 y 1989, gracias a una beca Fulbright, Ugalde vive en Nueva York junto a su mujer, Patricia Gadea. Allí creará el grupo de artistas Estrujenbank, formado por Ugalde, su esposa y Manuel Dimas. Al volver a Madrid en 1989, las actividades del grupo se intensifican: publican una revista, abren una galería, realizan varias exposiciones en España e Italia, presentan algunas acciones, hacen talleres creativos en la Facultad de Bellas Artes de Cuenca, y aparece un libro colectivo del grupo: Los tigres se perfuman con dinamita. El grupo también realizará una serie de videos que serán emitidos por el programa de TVE Metropolis.

El grupo Estrujenbank es efímero, y todas sus obras, a pesar de estar firmadas colectivamente, cabe atribuírselas a Ugalde ${ }^{66}$.

Desde el inicio del texto se trasmite la idea de que el nombre de Patricia Gadea está ahí por ser la esposa de Ugalde, que su papel en Estrujenbank fue de mero acompañamiento, pero por si no hubiera quedado claro la última frase es rotunda: "todas sus obras, a pesar de estar firmadas colectivamente, cabe atribuírselas a Ugalde". Frente a esta idea, refiriéndose a este periodo de Estrujenbank, Dionisio Cañas que fue testigo directo y cercano pone el acento en el proyecto compartido, diciendo que "influyeron enormemente, tanto su esposo como ella, en los cambios estéticos que ocurrieron en la última década del siglo pasado en España". Ambos compartieron durante este periodo una misma visión del arte, un lenguaje común caracterizado por la ironía iconoclasta y el recurso del apropiacionismo ${ }^{67}$. Lenguaje

64. Dionisio Cañas definió Estrujenbank como "la mosca en la leche del arte español".

65. http://www.estrujenbank.com.es/biografia.htm (Consultada el 7 de Julio de 2014).

66. MAS, R.: "Juan Ugalde". En La pintura española. Nuevas tendencias. Carroggio, 2006, p. 112. El subrayado es mío.

67. Esta idea de lenguaje compartido y construido a dos es recogido por ARROYO FERNÁN- 
al que Patricia se mantendrá fiel tras la separación de Ugalde y la disolución de Estrujenbank, siendo un período en que su obra se carga de un feminismo combativo e irónico ${ }^{68}$, del que salieron "algunos de sus mejores cuadros y unos magníficos dibujos y acuarelas" ${ }^{69}$.

A pesar de la fuerza de esta creadora y de su obra, se la ha querido hacer dependiente del que fuera su marido y otros artistas que la rodearon. Ella sin embargo se definía así en el año 1993: "Como mujer artista, no necesito ningún domador; el látigo ahora está en manos del destino. No soy un payaso roto ni una vedette subida a un elefante: soy Patricia Gadea acariciando una pantera negra, que es el arte, aunque quizá me muerda"70.

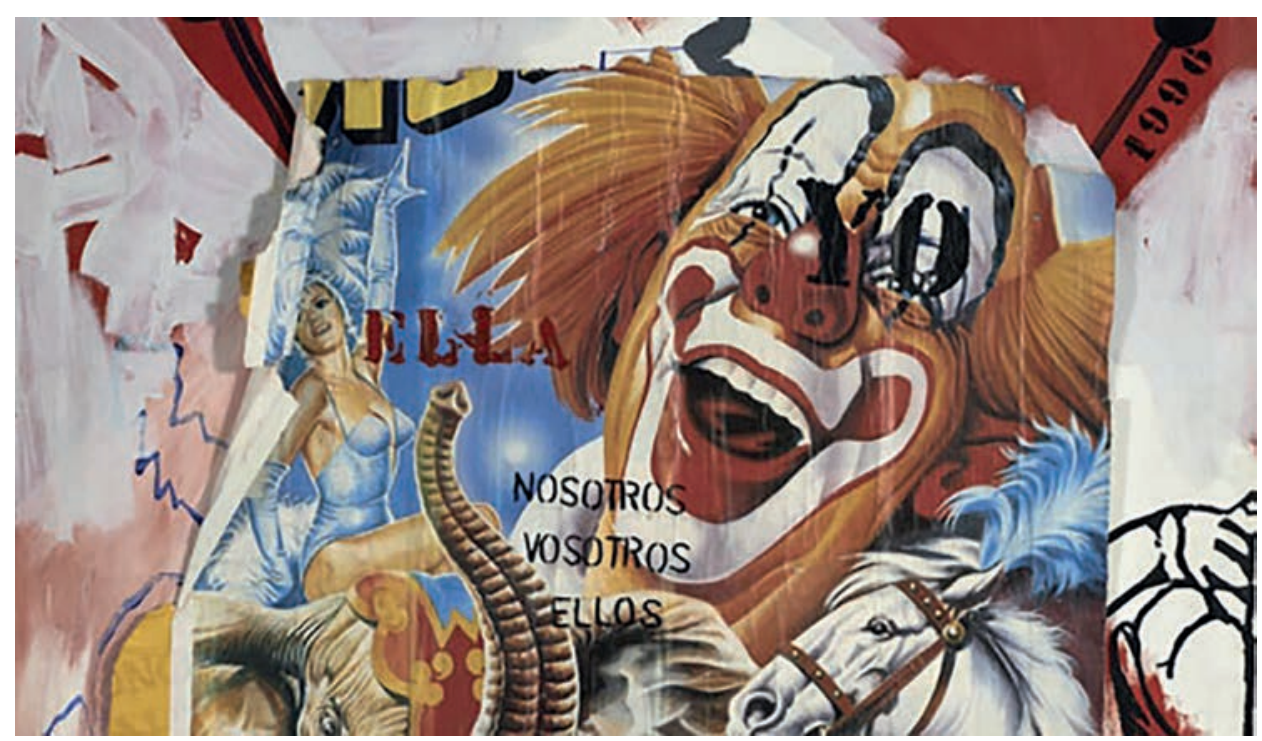

Fig. 6. Patricia Gadea. Patosa/Europa. Museo Reina Sofia.

DEZ, M. ${ }^{a}$ Dolores: "Inserción del comic en el ámbito de la Pintura II: De Juan Ugalde y Patricia Gadea al Equipo Límite”. http://www.patriciagadea.com.es/ (Consultado el 7 de julio de 2015).

68. "La mujer está en el centro de la obra de Patricia Gadea: la mujer como tema de la mujer, la mujer artista, la mujer madre, la mujer rebelde, la mujer de armas tomar, la mujer en guerra contra la mujer juguete del hombre, la mujer que lucha por ser una mujer integral, plena, que reclama el derecho a ser madre, artista y mujer sin ceder ni un milímetro de su libertad, de su derecho a ser todo a la vez". CAÑAS, Dionisio: "Patricia Gadea, entre la luz y la muerte". Fronterad Revista Digital. 27-12-2012.

69. http://www.patriciagadea.com.es/ (Consultado el 7 de julio de 2015).

70. CAÑAS, Dionisio: "Patricia Gadea, entre la luz (...)". 
El 14 de Abril 2006 Patricia fue encontrada muerta en su casa de Palencia. Durante unos años la obra de Patricia Gadea parecía condenada a caer bajo el manto esa segunda muerte que es el olvido. Pero tras una exposición retrospectiva titulada Atomic-Circus, organizada por el Museo Nacional Reina Sofía a finales del año 2014 y comisariada por Virginia Torrente, se sorteó este peligro ${ }^{71}$ y la obra de Gadea se puso en valor como uno de los referentes del arte español de las décadas de los 80 y 90 del siglo XX.

Este último caso, tan cercano en el tiempo, pone de manifiesto cómo los viejos esquemas de supeditación y desvalorización de la obra de las mujeres siguen vigentes. Porque a pesar de las décadas de igualdad formal, en las mentalidades se sigue manteniendo el paradigma androcéntrico en todos los ámbitos de la cultura.

\section{Referencias bibliográficas}

ALARIO TRIGUEROS, Teresa: Arte y feminismo. San Sebastián. Editorial Nerea, 2008.

ALARIO TRIGUEROS, Teresa: “Tejer y narrar en la plástica española contemporánea”. En PULEO, Alicia (coord.): Ecología y género en diálogo interdisciplinar. Madrid, Editorial Plaza y Valdés, 2015, pp. 241-262.

AVIA, Amalia: De puertas adentro: Memorias. Madrid, Taurus, 2004.

BOZAL, Valeriano: Arte del siglo XX en España (T. 2). Madrid, Espasa Calpe, 1995.

CALVO SERRALLER, Francisco: España medio siglo de arte de vanguardia 1939-1985. Madrid, Fundación Santillana, Ministerio de Cultura. 1985.

CSIKSZENTMIHALYI, Mihàly: Creatividad, el fluir y la psicología del descubrimiento y de la invención. Madrid, Paidós, 1998.

CHADWICK, Whitney y COURTIVRON, Isabelle: Los otros importantes. Creatividad y relaciones intimas. Valencia, Cátedra, 1994.

DOMÍNGUEZ, Susana: "Relaciones entre el arte y la información. El caso del realismo madrileño". Revista Latina de Comunicación Social, 21 (septiembre 1999).

GREER, Germaine: La carrera de obstáculos. Vida y obra de las pintoras antes de 1950. Madrid, Ediciones Bercimuel, 2005.

GUILLÉN, Esperanza: Retratos del genio. Culto a la personalidad artística en el siglo XIX. Madrid, Cátedra, 2007.

LÓPEZ, Pilar: Mujeres españolas en las artes plásticas. Madrid, Síntesis, 2003.

LÓPEZ, Pilar, “Artistas españolas en la dictadura de Franco (1939-1975)". Espacio, Tiempo, Forma, 3 (2015).

MARZO, José Luis y MAYAYO, Patricia: Arte en España (1939-2015). Ideas, prácticas, políticas. Madrid, Cátedra, 2015.

MOLINOS NAVARRO, Natalia: "Juana Francés siempre a la vanguardia. Sus etapas artísticas" Archivo de arte valenciano, 92 (2011) 387-400.

71. Peligro que existió verdaderamente, como se pone de manifiesto en la oscuridad que se mantuvo su obra tras su muerte durante ocho años, a pesar de que se haya escrito a posterior que "era y es más que recordada, más que respetada, más que valorada.” (http://www.eldiario.es/cultura/arte/ visiones-post-pop-Patricia-Gadea_0_326867494.html) (Consultado el 7 de julio de 2015). 
MOLINOS NAVARRO, Natalia: “Juana Francés. Una vocación, una pasión”. En VV. AA.: Catálogo de Juana Francés. Zaragoza, IAACC Pablo Serrano. Gobierno de Aragón, 2012, pp. 11-48.

POPOPVICI, Cirilo: J. Francés. Madrid, Ministerio de Educación y Ciencia, 1976.

TORRENTE, Virginia et al.: Patricia Gadea. Atomic Circus. Madrid, Museo Nacional Centro de Arte Reina Sofía, 2014.

TUSELL, Javier: "Compañeros en Madrid: Anatomía de un grupo generacional". En VV. AA.: Otra realidad. Compañeros en Madrid. Madrid, Caja Madrid. Fundación Humanismo y Democracia, 1992.

\section{Páginas web}

CAÑAS, Dionisio: "Patricia Gadea, entre la luz y la muerte". Fronterad Revista Digital, 27-12-2012. (Consultado el 20 de enero 2017).

ESTRUJENBANK: http://www.estrujenbank.com.es/biografia.htm (Consultado el 20 de diciembre de 2016).

LÓPEZ-FERNÁNDEZ. CAO, Marián: "Del mito de la creatividad pura a un enfoque sistémico, Web m-arte y cultura visual, 2014. http://www.m-arteyculturavisual.com/2012/10/15/del-mito-de-lacreatividad-pura-a-un-enfoque-sistemico-de-genero-en-la-construccion-de-la-persona-creadora/ (Consultado el 1 de julio de 2016). 